Vanessa Luz e Calil

\title{
Desenvolvimento de substratos poliméricos avançados para aplicação em dispositivos orgânicos flexíveis
}

Dissertação apresentada como requisito parcial para obtenção do grau de Mestre pelo Programa de Pós-graduação em Física do Departamento de Física da PUC-Rio

Orientador : Prof. Marco Cremona Co-Orientador: Dr. Cristiano Legnani 


\title{
Vanessa Luz e Calil
}

\section{Desenvolvimento de substratos poliméricos avançados para aplicação em dispositivos orgânicos flexíveis}

Dissertação apresentada como requisito parcial para obtenção do grau de Mestre pelo Programa de Pós-graduação em Física do Departamento de Física do Centro Técnico Científico da PUCRio. Aprovada pela Comissão Examinadora abaixo assinada.

\author{
Prof. Marco Cremona \\ Orientador \\ Departamento de Física - PUC-Rio
}

Prof. Cristiano Legnani

Co-Orientador

INMETRO

Prof. Marcelo Eduardo Huguenin Maia da Costa

Departamento de Física - PUC-Rio

\author{
Prof. Sidney Jose Lima Ribeiro \\ UNESP-Araraquara
}

Prof. José Eugênio Leal Coordenador Setorial do Centro Técnico Científico - PUC-Rio 
Todos os direitos reservados. É proibida a reprodução total ou parcial do trabalho sem autorização da universidade, do autor e do orientador.

\section{Vanessa Luz e Calil}

Possui graduação em Física pela Universidade de São Paulo, Campus São Carlos (2006). Tem experiência na área de Física, com ênfase em instrumentação específica de uso geral em Física, atuando principalmente nos seguintes temas: dispositivos orgânicos baseados em pequenas moléculas, óxidos condutores transparentes, polímeros.

Ficha Catalográfica

Calil, Vanessa Luz

Desenvolvimento de substratos poliméricos avançados para aplicação em dispositivos orgânicos flexíveis / Vanessa Luz e Calil; orientador: Marco Cremona; co-orientador: Cristiano Legnani. - Rio de Janeiro : PUC-Rio, Departamento de Física, 2010.

v., 109 f: il. ; $29,7 \mathrm{~cm}$

1. Dissertação (mestrado) - Pontifícia Universidade Católica do Rio de Janeiro, Departamento de Física.

Inclui referências bibliográficas.

1. Física - Tese. 2. Dispositivos orgânicos;. 3. eletrônica flexível;. 4. óxidos condutores transparentes; . 5. OLED;. 6. filmes finos;. 7. pulverização catódica;. 8. poli(éter imida);. 9. celulose bacteriana.. I. Cremona, Marco. II. Legnani, Cristiano. III. Pontifícia Universidade Católica do Rio de Janeiro. Departamento de Física. IV. Título. 
À minha família, que me apóia e me atura. 


\section{Agradecimentos}

À minha família, como um todo, pelo carinho. minha mãe, Zélia Mirtes Luz, pelo esforço e dedicação, pelo amor, carinho, apoio moral e financeiro, por acreditar em mim e em minhas decisões. Aos meus irmãos, mãe e avó pelo exemplo de vida.

Ao Diogo por todo amor, paciência, palavras de apoio e a distância, parte importante de nosso relacionamento!

Ao Eudes pela preocupação e bondade, pelos almoços de sábado ou domingo, por emprestar um fiador de forma que pudesse ter um teto.

Ao meu orientador e co-orientador, Marco Cremona e Cristiano Legnani, 
pela confiança, ensinamentos e reconhecimento.

Ao Prof. Carlos Achete pela confiança, e toda equipe Dimat/Inmetro pela amizade e palavras de incentivo.

Em especial agradeço à Gaby pela apresentação à PEI, pelas discussões, ensinamentos, e pela amizade, risadas e fofocas. À Ciça pela paciência ao fazer milhares de imagens de AFM, pelo incentivo e amizade. Ao Rogério Machado pelos muitos espectros de raios-X, explicações e piadas. Ao Alexei pelas discussões e ensinamentos. Ao Hernane pelas lições sobre CB.

Aos Funcionários e Professores do Departamento de Física da PUC-Rio pelas ajudas de última hora.

Ao Sérgio pela amizade e carinho, e pelas ajudas em química quando eu não conseguia nem formular a pergunta!

Aos amigos de outras salas da PUC pelos convites ao Pires e/ou Garota e/ou BG e/ou Lapa, fundamental para o não enlouquecimento natural de estudantes (principalmente de física).

Aos amigos do Cavernão, Rafael Mendes, Rafael Coutinho, César, Eric, Lucas, Paula e Leila, pela ajuda, pelas músicas, pelas risadas, pelos seriados e pelas conversas.

Aos amigos de São Carlos que mesmo longe torceram e torcem por mim. À Castanha pela amizade, carinho e preocupação, e principalmente por me abrigar em sua casa quando eu não tinha uma.

Às amigas de Monte Santo de Minas, Carol, Juliana e Poliana, por não me abandonarem quando eu me afastei.

Às minhas amiguinhas de casa pela sorte de nos darmos tão bem. À Mary por apresentar os vários sabores de Zhumir, essencial para cortar o estresse do dia-a-dia. À Kelly por vir e não me deixar sozinha nesta terra tão distante.

À SABIC e à Fibrocel pelo fornecimento dos polímeros PEI e CB utilizados nesta dissertação.

Ao CNPq, RENAMI, e FAPERJ pelo auxílio financeiro, sem o qual seria impossivel a realização deste trabalho. 


\section{Resumo}

Calil, Vanessa Luz; Cremona, Marco (Orientador); Legnani, Cristiano (Co-Orientador). Desenvolvimento de substratos poliméricos avançados para aplicação em dispositivos orgânicos flexíveis. Rio de Janeiro, 2010. 109p. Dissertação de Mestrado — Departamento de Física, Pontifícia Universidade Católica do Rio de Janeiro.

Neste trabalho, desenvolveram-se dois tipos de substratos flexíveis para dispositivos orgânicos. Para tal, usou-se o termoplástico comercial de alto desempenho, poli(éter imida) (PEI), e a celulose bacteriana (CB), um polímero natural e biocompatível comumente utilizado como pele artificial. Os filmes de PEI foram fabricados com boa transparência óptica no visível, flexibilidade e ausência de poros, enquanto os filmes de CB foram utilizados como recebidos. Filmes finos de óxido de índio dopado com estanho (ITO) foram depositados sobre os filmes, utilizando a técnica de rf-sputtering, a fim de torná-los condutores elétricos para serem utilizados em dispositivos. Os valores de resistividade elétrica dos substratos modificados foram aprimorados através da variação dos parâmetros de deposição dos filmes de ITO. Os menores valores de resistividade alcançados foram $3,27 \times 10^{-4} \Omega \cdot \mathrm{cm}$ para os substratos de PEI e $3,70 \times 10^{-4} \Omega \cdot \mathrm{cm}$ para os de $\mathrm{CB}$, comparáveis ao valor alcançado para os substratos de vidro $\left(3,66 \times 10^{-4} \Omega \cdot \mathrm{cm}\right)$, utilizados como referência. Além disso, devido às ótimas propriedades térmicas da PEI, os filmes de ITO sobre este material e sobre vidro passaram por um tratamento térmico a fim de baixar ainda mais o valor da resistividade. Após este tratamento, os valores de resistividade baixaram para $2,88 \times 10^{-4} \Omega \cdot \mathrm{cm}$ e $3,41 \times 10^{-4} \Omega \cdot \mathrm{cm}$, para a PEI e o vidro, respectivamente. Os resultados obtidos são comparáveis ou melhores àqueles obtidos por outros autores em diferentes substratos, com e sem tratamento térmico, e mostraram-se promissores para o desenvolvimento de dispositivos orgânicos flexíveis.

\section{Palavras-chave}

Dispositivos orgânicos; eletrônica flexível; óxidos condutores transparentes; OLED; filmes finos; pulverização catódica; poli(éter imida); celulose bacteriana. 


\section{Abstract}

Calil, Vanessa Luz; Cremona, Marco (Advisor); Legnani, Cristiano (Co-Advisor). Development of advanced polymeric substrates for application in flexible organic devices. Rio de Janeiro, 2010. 109p. MSc Dissertation — Departamento de Física, Pontifícia Universidade Católica do Rio de Janeiro.

In this work, it has developed two types of flexible substrates for organic devices. For this purpose, it was used the commercial high-performance thermoplastic, poly(ether imide) (PEI), and a natural and biocompatible polymer commonly used as artificial skin, bacterial cellulose (BC). PEI films were fabricated with good optical transparency in the visible range of spectra, flexibility and absence of pores, while the CB films were used as received. Thin films of indium tin oxide (ITO) were deposited on those films using rf magnetron sputtering in order to turn them electrical conductors for using in organic devices. The electrical resistivity of the modified substrates was improved by varying the ITO films deposition parameters. The lowest achieved resistivity was $3.27 \times 10^{-4} \Omega \cdot \mathrm{cm}$ for PEI substrates and $3.70 \times 10^{-4} \Omega \cdot \mathrm{cm}$ for CB substrates, comparable to the reference substrate (glass) $3.66 \times 10^{-4} \Omega \cdot \mathrm{cm}$. In addition, due to the excellent thermal properties of PEI, ITO films on this material and on glass substrates were thermally treated to further improvement of its electrical properties. After this treatment, the resistivity values decreased to $2.88 \times 10^{-4} \Omega \cdot \mathrm{cm}$ and $3.41 \times 10^{-4} \Omega \cdot \mathrm{cm}$ for PEI and glass substrates, respectively. The obtained results are comparable or better than those obtained by other authors on different substrates, with and without heat treatment, establishing these materials as outstanding substrates for the development of flexible organic devices.

\section{Keywords}

Organic devices; flexible electronics; transparent conducting oxides; OLED; thin films; magnetron sputtering; poly(ether imide); bacterial cellulose. 


\section{Sumário}

1 Introdução $\quad 16$

$\begin{array}{lll}1.1 & \text { Dispositivos } & 17\end{array}$

1.2 Dispositivos orgânicos emissores de luz (OLEDs) 18

$\begin{array}{lll}1.3 & \text { Substratos } & 23\end{array}$

1.4 Óxidos condutores transparentes (TCOs) 27

1.5 Compostos orgânicos 29

2 Fundamentação Teórica 30

2.1 Semicondutores 30

2.2 Propriedades elétricas 32

2.3 Propriedades ópticas 36

2.4 Propriedades físicas dos filmes de óxido de índio dopado com estanho (ITO) 39

2.5 Pulverização catódica 41

3 Métodos Experimentais $\quad 45$

3.1 Substratos flexíveis utilizados $\quad 45$

3.2 Limpeza dos substratos $\quad 51$

3.3 Deposição de filmes finos de ITO 52

3.4 Pré-tratamento térmico dos filmes de PEI 55

3.5 Tratamento térmico dos filmes finos de ITO sobre vidro e PEI 56

3.6 Fabricação dos OLEDs 56

3.7 Métodos e equipamentos de análise 57

4 Resultados e Discussões $\quad 61$

4.1 Análise dos filmes de PEI 61

4.2 Análise dos filmes de CB 68

4.3 Caracterização dos filmes finos de ITO 69

5 Considerações Finais $\quad 98$

$\begin{array}{ll}\text { Referências Bibliográficas } & 101\end{array}$ 


\section{Lista de figuras}

1.1 Estrutura básica de um OLED.

1.2 Evolução da estrutura dos OLEDs. Na figura, HIL = camada injetora de buracos (hole injecting layer), $\mathrm{HTL}=$ camada transportadora de buracos (hole transporting layer), EML = camada emissiva (emitting layer), $\mathrm{HBL}=$ camada bloqueadora de buracos (hole blocking layer), ETL = camada transportadora de elétrons (electron transporting layer), PIN = Positivo, Intrínseco e Negativo, é uma junção realizada com um semicondutor orgânico dopado tipo "p", um semicondutor orgânico "intrínseco" e um semicondutor orgânico dopado tipo " $n$ ".

1.3 a) Representação de um hipotético dispositivo retrátil para as forças armadas dos Estados Unidos da América em parceria com a Universidade do Estado do Arizona (EUA). b) Primeiro dispositivo flexível disponível comercialmente, Readius $\AA$, desenvolvido pela Polymer Vision.

1.4 Temperatura de transição vítrea $(\mathrm{Tg})$ de polímeros comercialmente disponíveis (CHOI;KIM;HA,2008).

2.1 Bandas de energia para materiais metálicos, semicondutores e isolantes.

2.2 Semicondutores dopados com impurezas tipo-n e tipo-p. 31

2.3 Desenho esquemático do efeito Hall.

2.4 Montagem experimental recomendada pelo NIST para realização de medidas de resistividade e efeito Hall através do método de Van der Pauw.

2.5 Estrutura do óxido de índio: a)célula unitária, b)átomo de índio localizado no centro de um octaedro levemente distorcido e c) altamente distorcido (PAINE;YEOM;YAGLIOGLU,2005).

2.6 Bandas de energia do óxido de índio dopado com estanho.

2.7 Esquema dos efeitos de partículas energéticas bombardeando uma superfície (OHRING, 1992).

3.1 Arranjo das fibrilas, microfibrilas, e celulose na parede celular.

3.2 Formação da película de celulose bacteriana na superfície de meio de cultura (Hestrim-Schramm) para diferentes cepas de bactérias.

3.3 Imagem de microscopia eletrônica de varredura de biocelulose (esquerda) e de celulose de plantas (direita) (SUTHERLAND,1998). 47

3.4 a) Dispositivo orgânico para fototerapia dinâmica. b) Aparelho portátil completo para realização do tratamento. Dispositivo desenvolvido por Ifor Samuel da Universidade de St Andrews, Escócia. Imagens extraídas de (WILLIAMS,2007).

3.5 Estrutura molecular da poli(éter imida) (PEI). 50

3.6 Esquema do processo de fabricação dos filmes de PEl. 51

3.7 Sistema de deposição e caracterização de dispositivos do LADOR. 54

3.8 Esquema da câmara de deposição de metais. 
3.9 Camadas utilizadas para fabricação dos OLEDs.

3.10 Panela de alumina usada para as análises de TGA (esquerda), panela e tampa de alumínio utilizada para as análises de DSC (direita). 58

3.11 Equipamento de medida e porta amostra para medidas de efeito Hall da ECOPIA Hall Effect Measurement System HS 3000.

4.1 TGA da pastilha e do filme de PEI.

4.2 Análise de DSC da pastilha e do filme de PEI.

4.3 Espectro FTIR de filmes de PEI, sem tratamento térmico e após tratamento a $573 \mathrm{~K}$.

4.4 Espectro de transmitância óptica do filme de PEI.

4.5 Imagem de MEV da seção transversal de um filme de PEI com aumento de $100 \times$. A porção branca da imagem representa a superfície do filme e o quadrado vermelho indica o aumento realizado na próxima imagem.

4.6 Imagem de MEV da seção transversal de um filme de PEI com um aumento de $2380 \times$. O quadrado vermelho indica o aumento realizado na próxima imagem.

4.7 Imagem de MEV da seção transversal de um filme de PEI com aumento de $10000 \times$.

4.8 Espectro de difração de raios-X do filme de PEI.

4.9 Espectro de transmitância óptica do filme de CB.

4.10 Esquema de montagem para determinação da confiabilidade da deposição dos filmes finos de ITO.

4.11 Gráfico ilustrando a dependência da espessura do filme de ITO com a posição no porta-substratos. O filme de ITO foi depositado a $60 \mathrm{~W}$ de potência de rf e $20,0 \times 10^{-2} \mathrm{~Pa}$ de pressão de trabalho.

4.12 Taxa de deposição dos filmes de ITO crescidos a $26,7 \times 10^{-2} \mathrm{~Pa}$ de pressão de trabalho em função da potência de rf.

4.13 Propriedades elétricas dos filmes produzidos a pressão de trabalho de $26,7 \times 10^{-2} \mathrm{~Pa}$ em função da potência de rf.

4.14 Difração de raios- $X$ de amostras preparadas a pressão de trabalho de $26,7 \times 10^{-2} \mathrm{~Pa}$ e a diferentes potências de rf $(50 \mathrm{~W}$ e $80 \mathrm{~W})$. No gráfico estão indicados alguns dos picos de refração referentes à estrutura cristalina do ITO.

4.15 Transmissão óptica dos filmes de ITO depositados a $26,7 \times 10^{-2} \mathrm{~Pa}$ de pressão de trabalho em função da potência de $\mathrm{rf}$, calculada pela média entre $450-800 \mathrm{~nm}$.

4.16 Taxa de deposição dos filmes de ITO crescidos a $50 \mathrm{~W}$ de potência de rf em função da pressão de trabalho.

4.17 Propriedades elétricas dos filmes de ITO em função da pressão de trabalho. Potência de rf de $50 \mathrm{~W}$.

4.18 Espectro de raios- $X$ dos filmes de ITO depositados a diferentes pressões de trabalho e potência de rf de $50 \mathrm{~W}$. No gráfico estão indicados alguns dos picos referentes à estrutura cristalina do ITO.

4.19 Propriedades elétricas dos filmes de ITO depositados à $50 \mathrm{~W}$ de potência de $\mathrm{rf}$ em função da pressão de trabalho (superiores a $\left.6,7 \times 10^{-2} \mathrm{~Pa}\right)$. 
4.20 Transmissão óptica dos filmes de ITO depositados a $50 \mathrm{~W}$ de potência de rf em função da pressão de trabalho, calculada pela média entre 450 - $800 \mathrm{~nm}$.

4.21 Constante de absorção óptica ao quadrado em função da energia para cálculo da energia da banda proibida dos filmes de ITO produzidos. Gráfico inserido: Banda proibida em função da pressão de trabalho.

4.22 Gráfico das propriedades elétricas do ITO em função da temperatura do tratamento térmico.

4.23 Espectro de raios- $X$ dos filmes de ITO depositados a $80 \mathrm{~W}$ de potência de rf e $26,7 \times 10^{-2} \mathrm{~Pa}$ de pressão de trabalho, tratados a diferentes temperaturas.

4.24 Imagens topográficas de AFM dos filmes de ITO sobre vidro tratados termicamente a: a) temperatura ambiente, b) $423 \mathrm{~K}, \mathrm{c}$ ) $473 \mathrm{~K}$, d) $523 \mathrm{~K}$, e) $573 \mathrm{~K}$.

4.25 Propriedades elétricas dos filmes de ITO sobre $\mathrm{PEI}$ produzidos a pressão de trabalho de $26,7 \times 10^{-2} \mathrm{~Pa}$ em função da potência de $\mathrm{rf}$.

4.26 Espectro de raios-X de ITO depositado sobre PEI a $50 \mathrm{~W}$ e a $80 \mathrm{~W}$ de potência e $26,7 \times 10^{-2} \mathrm{~Pa}$ de pressão.

4.27 Propriedades elétricas dos filmes de ITO sobre PEI depositados a $50 \mathrm{~W}$ de potência em função da pressão de trabalho.

4.28 Espectro de raios-X de ITO sobre PEl depositado a $50 \mathrm{~W}$ de potência de rf e $6,7 \times 10^{-2} \mathrm{~Pa}$ de pressão de trabalho.

4.29 Propriedades elétricas dos filme de ITO sobre PEI depositados a $50 \mathrm{~W}$ de potência de rf em função da pressão de trabalho (superiores a $\left.6,7 \times 10^{-2} \mathrm{~Pa}\right)$.

4.30 Gráfico das propriedades elétricas do ITO sobre PEI em função da temperatura do tratamento térmico.

4.31 Espectro de difração de raios- $X$ de filmes de ITO sobre PEI depositados a $50 \mathrm{~W}$ de potência de $\mathrm{rf}, 13,3 \times 10^{-2} \mathrm{~Pa}$ de pressão com $150 \mathrm{~nm}$ de espessura e tratados termicamente a $423 \mathrm{~K}, 473 \mathrm{~K}$ e $523 \mathrm{~K}$ (CALIL et al.,2009).

4.32 Imagens topográficas de AFM dos filmes de ITO sobre PEI tratados termicamente a: a) temperatura ambiente, b) $423 \mathrm{~K}$, c) $473 \mathrm{~K}$, d) $523 \mathrm{~K}$, e) $573 \mathrm{~K}$.

4.33 Propriedades elétricas dos filmes de ITO sobre CB produzidos a pressão de trabalho de $26,7 \times 10^{-2} \mathrm{~Pa}$ e diferentes potências de $\mathrm{rf}$.

4.34 Difração de raios- $X$ de amostras de ITO sobre CB preparadas a pressão de trabalho de $26,7 \times 10^{-2} \mathrm{~Pa}$ e a diferentes potências de rf, $50 \mathrm{~W}$ e $80 \mathrm{~W}$. Gráfico inserido: Aumento do gráfico na região entre $25^{\circ}$ e $40^{\circ}$ onde estão indicados os picos do ITO (222) e (400). 92

4.35 Propriedades elétricas do filme de ITO sobre CB em função da pressão de trabalho. Potência de rf de $50 \mathrm{~W}$.

4.36 Espectro de raios- $X$ dos filmes de ITO sobre CB depositados a diferentes pressões de trabalho e potência de rf de $50 \mathrm{~W}$. Entre parênteses estão indicados alguns dos picos referentes à estrutura cristalina do filme de ITO. 
4.37 Propriedades elétricas dos filmes de ITO sobre CB depositados a $50 \mathrm{~W}$ de potência de rf em função da pressão de trabalho (superiores a $\left.6,7 \times 10^{-2} \mathrm{~Pa}\right)$.

5.1 OLED preliminar fabricado sobre substrato de a) PEI e b) CB. Camadas orgânicas utilizadas: $\mathrm{Alq}_{3} / \mathrm{NPB} / \mathrm{CuPC}$. 


\section{Lista de tabelas}

1.1 Propriedades dos substratos flexíveis (WONG;SALLEO,2009). 26

1.2 Exemplos das aplicações de diferentes tipos de funcionalização de superfícies por diferentes processos.

4.1 Valores médios e desvios padrões da espessura do ITO depositado sobre silício em função da posição no porta-substratos.

4.2 Cálculo estimado dos erros associados às propriedades elétricas e à espessura do ITO depositados sobre vidro e silício, respectivamente. 71

4.3 Deposições de ITO a pressão de trabalho de $26,7 \times 10^{-2}$ Pa e respectivas características do filme depositado sobre vidro.

4.4 Deposições de ITO a potência de rf de $50 \mathrm{~W}$ e respectivas características do filme depositado sobre vidro.

4.5 Combinação dos parâmetros de deposição que retornaram as menores resistividades para os filmes de ITO depositados sobre substratos de vidro.

4.6 Deposições de ITO a pressão de trabalho de $26,7 \times 10^{-2} \mathrm{~Pa}$ e respectivas características do filme depositado sobre $\mathrm{PEI}$.

4.7 Deposições de ITO sobre PEl a potência de rf de $50 \mathrm{~W}$ e respectivas características do filme depositado.

4.8 Combinação dos parâmetros de deposição que retornaram as menores resistividades para os filmes de ITO depositados sobre substratos de PEI.

4.9 Deposições de ITO sobre CB a pressão de trabalho de $26,7 \times 10^{-2} \mathrm{~Pa}$ e respectivas características do filme depositado.

4.10 Deposições de ITO sobre CB a potência de rf de $50 \mathrm{~W}$ e respectivas características do filme depositado.

4.11 Combinação dos parâmetros de deposição que retornaram as menores resistividades para os filmes de ITO depositados sobre substratos de CB.

4.12 Tabela comparativa dos resultados obtidos para a deposição de filmes de ITO sobre substratos de vidro, $\mathrm{PEI}$ e $\mathrm{BC}$, e resultados do tratamento térmico posterior dos filmes de ITO sobre vidro e PEI. 
Fazer um desenho nas costas da mão Despir a consciência das dores morais Jogar uma vaca do décimo andar Viajar sob a lua que varre os sertões Uma ostra chilena, um beijo em Paris Se cortasse o cabelo e mudasse o nariz Se Vital escrevesse a constituição Se eu nunca quisesse quem nunca me quis Ser dois e ser dez e ainda ser um Se a vingança apagasse a dor que eu senti Ser seco, ser reto, isento à moral Se eu nunca lembrasse o estrago que eu fiz

Tudo isso me faria feliz Absurdos me fariam feliz

Pero nada me hará tan feliz como dos margaritas

Paralamas do Sucesso, Severino. 